\title{
Applying the Transtheoretical Model to Physical Activity Behavior in Individuals With Non-Cystic Fibrosis Bronchiectasis
}

\author{
Jason J Wilson $\mathrm{PhD}$, Alison Kirk $\mathrm{PhD}$, Kate Hayes $\mathrm{PhD}$, Ian Bradbury $\mathrm{PhD}$, \\ Suzanne McDonough PhD, Mark A Tully PhD, Brenda O’Neill PhD, and Judy M Bradley PhD
}

\begin{abstract}
BACKGROUND: The transtheoretical model has been successful in promoting health behavior change in general and clinical populations. However, there is little knowledge about the application of the transtheoretical model to explain physical activity behavior in individuals with non-cystic fibrosis bronchiectasis. The aim was to examine patterns of (1) physical activity and (2) mediators of behavior change (self-efficacy, decisional balance, and processes of change) across stages of change in individuals with non-cystic fibrosis bronchiectasis. METHODS: Fifty-five subjects with non-cystic fibrosis bronchiectasis (mean age $\pm \mathrm{SD}=63 \pm 10 \mathrm{y}$ ) had physical activity assessed over $7 \mathrm{~d}$ using an accelerometer. Each component of the transtheoretical model was assessed using validated questionnaires. Subjects were divided into groups depending on stage of change: Group 1 (pre-contemplation and contemplation; $n=10$ ), Group 2 (preparation; $n=20$ ), and Group 3 (action and maintenance; $n=25$ ). Statistical analyses included one-way analysis of variance and Tukey-Kramer post hoc tests. RESULTS: Physical activity variables were significantly $(P<.05)$ higher in Group 3 (action and maintenance) compared with Group 2 (preparation) and Group 1 (pre-contemplation and contemplation). For self-efficacy, there were no significant differences between groups for mean scores $(P=.14)$. Decisional balance cons (barriers to being physically active) were significantly lower in Group 3 versus Group $2(P=.032)$. For processes of change, substituting alternatives (substituting inactive options for active options) was significantly higher in Group 3 versus Group $1(P=.01)$, and enlisting social support (seeking out social support to increase and maintain physical activity) was significantly lower in Group 3 versus Group $2(P=.038)$. CONCLUSIONS: The pattern of physical activity across stages of change is consistent with the theoretical predictions of the transtheoretical model. Constructs of the transtheoretical model that appear to be important at different stages of change include decisional balance cons, substituting alternatives, and enlisting social support. This study provides support to explore transtheoretical model-based physical activity interventions in individuals with non-cystic fibrosis bronchiectasis. (ClinicalTrials.gov registration NCT01569009.) Key words: behavioral research; respiratory tract diseases; physical activity; accelerometry. [Respir Care 2016;61(1):68-77. @ 2016 Daedalus Enterprises]
\end{abstract}

\section{Introduction}

Non-cystic fibrosis bronchiectasis (hereafter referred to as bronchiectasis) is a chronic respiratory disease charac-

Drs Wilson and Tully are affiliated with the Centre for Public Health, School of Medicine, Dentistry and Biomedical Sciences, Queen's University Belfast, Belfast, Northern Ireland. Drs Wilson and Tully, and Prof McDonough are affiliated with the UKCRC Centre of Excellence for Public Health, Belfast, Northern Ireland. Dr Kirk is affiliated with the School of Psychological Sciences and Health, University of Strathclyde, Glasgow, Scotland. Drs Hayes and O'Neill, and Profs Bradbury and terized by the presence of abnormal, irreversibly dilated, thick-walled bronchi which inhibit mucus clearance func-

\footnotetext{
McDonough are affiliated with the Centre for Health and Rehabilitation Technologies, Institute for Nursing and Health Research, Ulster University, Derry, Northern Ireland. Prof Bradley is affiliated with the Wellcome Trust-Wolfson Northern Ireland Clinical Research Facility, School of Medicine, Dentistry and Biomedical Sciences, Queen's University Belfast, Belfast, Northern Ireland.

This work was supported by the Physiotherapy Research Foundation (PRF), the Charitable Trust of the Chartered Society of Physiotherapy (PRF Award (11) A02) and supported by the Northern Ireland Clinical
} 
tion and have not been caused by cystic fibrosis. ${ }^{1-3}$ Common symptoms include chronic cough and sputum production, breathlessness, and fatigue. ${ }^{1-3}$ These symptoms are likely to contribute to reduced physical activity and exercise capacity. Although difficult to predict, prevalence is approximately 1:1,000 in the United Kingdom and 1:2,000 in the United States, with prevalence increasing with age. ${ }^{3}$ Bronchiectasis-associated health-care costs in the United States have been estimated at $\$ 630$ million annually, ${ }^{4}$ and associated hospital admissions vary between 2 and 6 per 100,000 in Europe. 5 Treatments for patients with bronchiectasis include prescribing oral and inhaled medications along with airway clearance, although poor adherence to these treatments has been highlighted. 3,6 Health-related behaviors are also recommended, and the promotion of physical activity and exercise in the management of bronchiectasis has been included in regional and national guidelines. ${ }^{7,8}$

Although research has been conducted with other respiratory groups,${ }^{9}$ little research has been conducted to explore physical activity in individuals with bronchiectasis. Recently published results from the Physical Activity in Bronchiectasis ${ }^{10}$ study explored physical activity levels in individuals with bronchiectasis and examined relationships between physical activity and clinical phenotype. In brief, few individuals with bronchiectasis met the recommended physical activity guidelines, with many demonstrating largely inactive lifestyles. ${ }^{10}$ No physical activity interventions have been conducted in individuals with bronchiectasis, highlighting the need for development of physical activity interventions that are tailored to this group.

The Medical Research Council ${ }^{11}$ guidance on developing and evaluating complex interventions emphasizes that researchers should first develop a theoretical understanding of the possible mechanisms of action by drawing on

\footnotetext{
Research Network Respiratory Health interest group. Dr Wilson was supported in part by the Department for Employment and Learning (Northern Ireland) as part of a PhD scholarship. The authors have disclosed no
} conflicts of interest.

Drs Wilson and Kirk are co-first authors.

Drs O’Neill and Bradley are co-senior authors.

Dr Wilson presented a version of this paper at the British Association of Sport and Exercise Sciences Student Conference, held April 8 and 9, 2014, in Portsmouth, United Kingdom, and at the Physiotherapy UK conference, held October 10 and 11, 2014, in Birmingham, United Kingdom.

Correspondence: Judy M Bradley PhD, Wellcome Trust-Wolfson Northern Ireland Clinical Research Facility, U Floor, Belfast City Hospital, Lisburn Road, Belfast, BT9 7AB, Northern Ireland. E-mail: judy.bradley@qub.ac.uk.

DOI: $10.4187 /$ respcare. 04154

\section{QUICK LOOK}

\section{Current knowledge}

The transtheoretical model is an integrative biopsychosocial model to conceptualize the process of change. In comparison with other behavior change models, which focus exclusively on one dimension of change, the transtheoretical model integrates key constructs from other theories into an inclusive theory of behavior change. The transtheoretical model has been successful in promoting health behavior change in subjects with diabetes but has not been studied in respiratory disease.

\section{What this paper contributes to our knowledge}

In a group of subjects with bronchiectasis, the findings from this study support the theoretical predictions of the transtheoretical model and the application of this model for physical activity intervention development. Constructs of the transtheoretical model that appear to be important at different stages of change include decisional balance cons, substituting alternatives, and enlisting social support.

existing research/psychological theories and/or by conducting new primary research before developing new interventions. Although a recent systematic review has queried the association between psychological theory and increased intervention effectiveness, ${ }^{12}$ guidelines for promotion of physical activity recommend that interventions should be based on valid theoretical frameworks ${ }^{13}$ and utilize behavior change techniques ${ }^{14}$ to understand the mechanism of action. However, most physical activity interventions in COPD have been developed without using a psychological theory. ${ }^{15}$ This makes it challenging to identify the behavior change techniques being targeted and to test these interventions in other chronic conditions. ${ }^{11}$

The transtheoretical model is an integrative biopsychosocial model to conceptualize the process of behavior change. In comparison with other behavior change models, which focus exclusively on one dimension of change, the transtheoretical model integrates key constructs from other theories ${ }^{16}$ into an inclusive theory of behavior change that can be applied to different behaviors and populations within different settings. ${ }^{17}$ The transtheoretical model was a prerequisite to the behavior change technique taxonomy because it lists discrete behavior change techniques (processes of change) used in interventions. ${ }^{18}$ The transtheoretical model has been successful in promoting health behavior change in the general population ${ }^{19}$ and in clinical populations, such as diabetes, ${ }^{20}$ and is starting to be used in lifestyle interventions in subjects with respiratory disease. ${ }^{21}$ 
Table 1. Description of Each Component of the Transtheoretical Model

\begin{tabular}{|c|c|}
\hline Transtheoretical Model Construct & Description \\
\hline \multicolumn{2}{|l|}{ Stages of change } \\
\hline Pre-contemplation & No intention to engage in regular physical activity \\
\hline Contemplation & Intention to engage in regular physical activity in next 6 mo. \\
\hline Preparation & Immediate intentions and commitment to engage in regular physical activity \\
\hline Action & Initiation of engagement in regular physical activity in last 6 mo. \\
\hline Maintenance & Maintenance of engagement of regular physical activity for longer than 6 mo. \\
\hline $\begin{array}{l}\text { Self-efficacy (question on having respiratory symptoms was } \\
\text { added to the original five questions) }\end{array}$ & $\begin{array}{l}\text { Personal confidence towards physical activity commitment when: tired/in a bad } \\
\text { mood/do not have time/on vacation/it is raining or snowing/having respiratory } \\
\text { symptoms }\end{array}$ \\
\hline \multicolumn{2}{|l|}{ Decisional balance } \\
\hline Pros & Perceived benefits of engaging in regular physical activity \\
\hline Cons & Perceived barriers to engaging in regular physical activity \\
\hline \multicolumn{2}{|l|}{ Cognitive Processes of Change } \\
\hline Increasing knowledge (consciousness raising) & $\begin{array}{l}\text { Finding information on the benefits of physical activity and the current } \\
\text { recommendations for physical activity }\end{array}$ \\
\hline Being aware of risks (dramatic relief) & Concern for the risks of being physically inactive \\
\hline Caring about consequences (environmental re-evaluation) & Realizing social and environmental benefits of physical activity \\
\hline Comprehending benefits (self-re-evaluation) & Assessing physical activity status and the values related to physical activity \\
\hline Increasing healthy opportunities (social liberation) & $\begin{array}{l}\text { Awareness, availability, and acceptance by the individual of physical activity in } \\
\text { society }\end{array}$ \\
\hline \multicolumn{2}{|l|}{ Behavioral processes of change } \\
\hline Substituting alternatives (counter-conditioning) & Substituting inactive options for active options \\
\hline Enlisting social support (helping relationships) & Seeking out social support to increase and maintain physical activity \\
\hline Rewarding oneself (reinforcement management) & Providing rewards for being more active \\
\hline Committing oneself (self-liberation) & Setting goals and making commitments for physical activity \\
\hline Reminding oneself (stimulus control) & $\begin{array}{l}\text { Controlling factors that have a negative effect on physical activity to prevent } \\
\text { relapse and using stimuli to increase physical activity level }\end{array}$ \\
\hline
\end{tabular}

The constructs outlined in the transtheoretical model consist of the stages of change and the mediators of change: self-efficacy, decisional balance, and processes of change (both cognitive and behavioral). Table 1 provides a description of each construct. Stage of change classifies an individual regarding his or her progression toward habitual physical activity and is hypothesized to relate with the other constructs of the transtheoretical model. ${ }^{22}$ The stages of change range from the pre-contemplation stage up to the maintenance stage. In a successful physical activity intervention, when stage progression occurs, self-efficacy to be physically active in different situations and the perceived pros/benefits to being physically active would be expected to increase, whereas perceived cons/barriers to being physically active would be expected to decrease. ${ }^{23}$ It has been suggested that cognitive processes are utilized more during movement around the earlier stages of change (pre-contemplation to contemplation or preparation) and that behavioral processes are utilized more during movement around the later stages of change (preparation for action or maintenance). ${ }^{23}$

However, a research agenda paper on the transtheoretical model ${ }^{24}$ reported that previous research that has explored the application of the transtheoretical model in healthy populations has been subject to methodological limitations, such as the use of subjective methods of measuring physical activity, and very few have examined all constructs of the model. Also, a systematic review of transtheoretical model-based physical activity behavior change interventions conducted in various populations reported that the majority of interventions purported to be based on the transtheoretical model failed to accurately represent all dimensions of the model. ${ }^{19}$ This means that the efficacy of such approaches cannot be fully determined.

One study has applied the transtheoretical model to explain physical activity behavior and promote behavior change in subjects with COPD. ${ }^{25}$ The main findings were that the most common processes of change used by subjects with COPD included substituting alternatives, committing oneself, and comprehending benefits. Subjects in the pre-contemplation stage also used significantly fewer processes of change compared with the other 4 stages. ${ }^{25}$ However, although the transtheoretical model has been applied to physical activity behavior in COPD, a recent systematic review exploring physical activity interventions in COPD has shown that no interventions have been based 
on the transtheoretical model. ${ }^{15}$ In particular, no relevant studies have been carried out in subjects with bronchiectasis.

This paper aims to examine patterns of (1) physical activity and (2) mediators of behavior change (self-efficacy, decisional balance, and processes of change) across stages of change in individuals with bronchiectasis. This will improve our understanding of physical activity behavior and will inform the development of physical activity interventions tailored to this population.

\section{Methods}

\section{Subject Selection and Study Design}

Full details relating to the subjects, study design, and study materials have been included in a previous paper. ${ }^{10}$ In brief, subjects with bronchiectasis were recruited from 3 hospitals in Northern Ireland. Inclusion criteria were: age $\geq 18 \mathrm{y}$, diagnosis of bronchiectasis confirmed either by computed tomography or high-resolution computed tomography $\leq 10$-pack-year smoking history, clinical stability (no pulmonary exacerbation), no significant change in symptoms or medication in the last 4 weeks and sputum bacteriology completed over the past 3 months. Exclusion criteria were: current severe hemoptysis, pregnancy, or any other concomitant condition that would prevent participation. Study recruitment occurred over 12 months, and subjects were recruited across all seasons. The study was approved by Northern Ireland Research Ethics Committees (Ethics Approval REC Reference: 12/NI/0044) and research departments of all participating hospitals. Written informed consent was obtained from all study subjects. Subjects were free to withdraw from the study at any stage with no explanation required.

The study design was cross-sectional using quantitative methodology. Age and sex were recorded during visit 1 , and body mass index and spirometry were also assessed. The ActiGraph GT3X+ accelerometer (ActiGraph, Pensacola, Florida) was fitted and worn for 7 consecutive d following visit 1 . Visit 2 was conducted $8 \mathrm{~d}$ after visit 1 , when subjects returned the accelerometer and activity monitoring diary and completed study questionnaires, spirometry, and the modified shuttle test. ${ }^{26}$ The study questionnaires were completed in a standardized order and were cross-checked for full completion by researchers during the study visits.

\section{Study Measurements}

Demographics and Clinical Phenotype. Subject characteristics were recorded, including age, sex, and body mass index. Height and mass were measured in light clothing and without shoes using Seca column scales (model
704; Seca, Hamburg, Germany). Spirometry ( $\mathrm{FEV}_{1}$ and FVC) was assessed using an ML3500 spirometer (CareFusion, San Diego, California) and classified according to American Thoracic Society/European Respiratory Society guidelines. ${ }^{27}$ The bronchiectasis severity index was used to classify subjects as having mild $(0-4)$, moderate (5-8), or severe $(9+)$ bronchiectasis based on 4 clinical end points (mortality, frequency of exacerbations, hospital admissions, and health-related quality of life). ${ }^{28}$ Exercise capacity was measured using the modified shuttle test, a progressive 15 -stage exercise field test adhering to a set protocol. ${ }^{29,30}$ The modified shuttle test was performed twice, with the highest distance (in meters) completed in either modified shuttle test used in the data analysis. The EQ-5D-5L health questionnaire ${ }^{31-33}$ was used as an assessment of health outcome, providing a single index value for health status and also allowing subjects to subjectively rate their current health status on a $0-100$ visual analog scale. The Quality of Life Questionnaire-Bronchiectasis ${ }^{34}$ assessed different domains of disease-specific health-related quality of life, including physical functioning, role functioning, vitality, emotional functioning, social functioning, treatment burden, health perception, and respiratory symptoms. Treatment burden was not included in the final results because 14 of 55 subjects did not use bronchiectasis treatments and therefore did not have a treatment burden score. The Leicester Cough Questionnaire ${ }^{35}$ assessed different aspects of health affected by chronic cough and has been shown to be sensitive at detecting changes in health status within an adult chronic cough population.

Physical Activity. Subjects wore the ActiGraph GT3X+ accelerometer during all waking hours for 7 consecutive full $\mathrm{d}$ only removing it during nighttime sleeping and water-based activities. The device was worn on an elastic belt and was positioned on the anterior axillary line of the hip on the dominant side. Wear-time validation was applied using the manufacturer's software (ActiLife 6.8.0) to apply recognized parameters. ${ }^{36}$ Valid data sets required at least $600 \mathrm{~min}$ of wear-time/d over at least $5 \mathrm{~d}$, with one being a Saturday or Sunday. ${ }^{37,38}$ Before analysis, data were summed in 15-s epochs. Daily physical activity parameters included minutes in light-lifestyle physical activity (100$1,951$ counts $/ \mathrm{min})^{39}$, minutes in total moderate to vigorous physical activity and minutes of moderate to vigorous physical activity in at least 10 -min bouts ( $\geq 1,952$ counts/min), 39 minutes in total physical activity based on $\geq 100$ counts $/ \mathrm{min},{ }^{40}$ step counts, activity energy expenditure based on the Freedson combination 1998 algorithm, ${ }^{39}$ and minutes in sedentary behavior $(<100 \text { counts/min })^{39}$

Constructs of the Transtheoretical Model. Table 1 includes details for each transtheoretical model questionnaire. The Stages of Change Questionnaire was used to 
clarify each subject's current stage of change in terms of physical activity behavior. ${ }^{41}$ The Self-Efficacy Questionnaire of Marcus et $\mathrm{al}^{42}$ provided information on subjects' confidence to undertake physical activity in different situations. An additional disease-specific question was included, which related to the barriers created by the typical symptoms of bronchiectasis, such as chronic cough and excessive sputum production. The Decisional Balance Questionnaire of Marcus et $\mathrm{al}^{43}$ assessed subjects' perceptions of the benefits and barriers to being physically active. The Processes of Change Questionnaire of Marcus et al ${ }^{23,44}$ described the strategies that subjects use to progress through the different stages of change.

\section{Statistical Analysis}

Descriptive statistics were used to summarize clinical phenotype, physical activity, and constructs of the transtheoretical model. Patterns in clinical phenotype, physical activity, and mediators of behavior change were analyzed across each individual stage of change and also in groups: Group 1, pre-contemplation and contemplation; Group 2, preparation; Group 3, action and maintenance. Because of small participant numbers in the pre-contemplation $(n=4)$ and action $(n=3)$ stages, the grouped approach was used in the reported analysis. Table 1 provides an explanation of each of the constructs of the transtheoretical model. Between-grouped stage analysis was conducted using oneway analysis of variance without correction for multiplicity. If, for any construct, the analysis of variance $P$ value was $<.05$, Tukey-Kramer post hoc tests were used to explore differences across the grouped stages of changes. This method of statistical analysis was conducted in similar studies exploring the application of the transtheoretical model to physical activity in older adults with type 2 diabetes and/or cardiovascular disease, ${ }^{20}$ in adults with COPD,${ }^{25}$ and in mothers based in the United States. ${ }^{45}$ Exploratory analysis within each of the grouped stages was conducted using paired sample $t$ tests to test differences in the overall mean of the 5 cognitive processes of change domains versus the overall mean of the 5 behavioral processes of change domains in each grouped stage.

Unless otherwise stated, summary data are reported as mean \pm SD. Results that are statistically significant also include mean differences and 95\% CI. Statistical analysis was performed using SPSS 20.0.0 for Windows (SPSS, Chicago, Illinois). Statistical significance was set at $P<.05$ (2-sided).

\section{Results}

Fifty-five subjects with bronchiectasis $(22 \mathrm{male} / 33 \mathrm{fe}-$ male; mean age $=63 \pm 10 \mathrm{y}$; mean $\mathrm{FEV}_{1}=76 \pm 21 \%$ of predicted) were recruited from 3 hospitals in Northern Ireland. Distribution across individual stages of change was: pre-contemplation $(n=4)$, contemplation $(n=6)$, preparation $(n=20)$, action $(n=3)$, and maintenance $(n=22)$. Using the grouped approach, subjects were divided into Group 1 (pre-contemplation and contemplation; $n=10$ ), Group 2 (preparation; $n=20$ ), and Group 3 (action and maintenance; $n=25$ ). Table 2 shows the differences in clinical phenotype across the stages of change. There were no significant differences in $\mathrm{FEV}_{1}$ percent of predicted $(P=.23)$ and bronchiectasis severity index scores $(P=.71)$ between groups. Group 2 had significantly higher body mass index compared with Group 3 $\left(3.5 \mathrm{~kg} / \mathrm{m}^{2}, 95 \% \mathrm{CI}: 0.6-6.4, P=.01\right)$. Group 1 and Group 2 achieved significantly lower modified shuttle test distances compared with Group 3 ( $-264 \mathrm{~m}$ 95\% CI: -495 to $-33, P=.02$ and $-207 \mathrm{~m} 95 \% \mathrm{CI}:-393$ to -22 , $P=.03$ ). Group 1 had significantly reduced Quality of Life Questionnaire-Bronchiectasis vitality scores compared with Group $3(-12.0,95 \%$ CI: -23.5 to -0.5 , $P=.040)$. There were no significant differences between groups for the other health-related quality of life parameters.

\section{Patterns in Physical Activity and Sedentary Behavior Across Stages of Change}

Table 3 highlights the distribution of physical activity measures across the stages of change. Group 2 had significantly reduced daily light-lifestyle physical activity time compared with Group 3 ( $-44 \mathrm{~min}, 95 \%$ CI: -87 to -1 , $P=.045$ ). Groups 1 and 2 had significantly reduced daily total moderate to vigorous physical activity time $(-16.6 \mathrm{~min}, 95 \% \mathrm{CI}:-33.2$ to $-0.1, P=.049$ and $-14.7 \mathrm{~min}, 95 \% \mathrm{CI}:-27.9$ to $-1.4, P=.03)$, daily total physical activity time ( $-69 \mathrm{~min}, 95 \% \mathrm{CI}:-132$ to -6 , $P=.030$ and $-58 \mathrm{~min}, 95 \% \mathrm{CI}:-109$ to $-8, P=.02$ ), and daily step counts $(-2,547$ steps, $95 \%$ CI: $-4,886$ to $-208, P=.03$ and $-2,034$ steps, $95 \%$ CI: $-3,909$ to $-158, P=.031$ ) compared with Group 3 respectively. There were no significant differences in moderate to vigorous physical activity in $\geq 10$-min bouts $(P=.14)$, activity energy expenditure $(P=.07)$, and sedentary behavior time between groups $(P=.83)$.

\section{Patterns in Mediators of Change Across Stages of Change}

The distribution of self-efficacy, decisional balance, and processes of change across the stages of change are included in Table 4. For self-efficacy, there were no significant differences between groups for mean scores $(P=.14)$. For decisional balance, Group 2 perceived significantly more cons/barriers to being physically active compared with Group 3 (0.56, 95\% CI: $0.41-1.08, P=.032)$. For processes of change, Group 1 used significantly fewer 
Table 2. Clinical Phenotype Across the Stages of Physical Activity Behavior Change

\begin{tabular}{|c|c|c|c|c|}
\hline Characteristics & $\begin{array}{l}\text { Pre-Contemplation and } \\
\text { Contemplation } \\
\text { (Group } 1 ; n=10)\end{array}$ & $\begin{array}{c}\text { Preparation } \\
\text { (Group } 2 ; n=20)\end{array}$ & $\begin{array}{c}\text { Action and } \\
\text { Maintenance } \\
\text { (Group } 3 ; n=25 \text { ) }\end{array}$ & $P$ \\
\hline Age, y & $63.5 \pm 9.6$ & $64.4 \pm 10.0$ & $62.8 \pm 10.3$ & .87 \\
\hline \multicolumn{5}{|l|}{ Sex } \\
\hline Male & 4 & 8 & 10 & NA \\
\hline Female & 6 & 12 & 15 & NA \\
\hline BMI, $\mathrm{kg} / \mathrm{m}^{2}$ & $26.7 \pm 4.8$ & $28.7 \pm 4.7 *$ & $25.2 \pm 2.8$ & $.02 \dagger$ \\
\hline $\mathrm{FEV}_{1}, \%$ predicted & $77.4 \pm 16.4$ & $70.0 \pm 23.3$ & $80.5 \pm 19.4$ & .23 \\
\hline FVC, $\%$ predicted & $90.3 \pm 14.8$ & $88.6 \pm 23.8$ & $100.9 \pm 15.2$ & .08 \\
\hline Bronchiectasis severity index ( $0-26,0$ best to 26 worst) & $5.10 \pm 3.28$ & $6.25 \pm 3.97$ & $5.80 \pm 3.44$ & .71 \\
\hline \multicolumn{5}{|l|}{ Smoking history } \\
\hline Never & 7 & 17 & 22 & NA \\
\hline Ex-smoker & 3 & 3 & 3 & NA \\
\hline MST, meters & $370 \pm 247 \ddagger$ & $427 \pm 258^{*}$ & $634 \pm 258$ & $.01 \dagger$ \\
\hline \multicolumn{5}{|l|}{ EQ-5D-5L health questionnaire } \\
\hline Index score $(0-1,0$ worst to 1 best $)$ & $0.76 \pm 0.22$ & $0.68 \pm 0.36$ & $0.85 \pm 0.14$ & .10 \\
\hline EQ-5D VAS score (0-100, 0 worst to 100 best) & $66.7 \pm 22.7$ & $72.1 \pm 20.8$ & $80.0 \pm 11.3$ & .10 \\
\hline \multicolumn{5}{|c|}{ Quality of Life-Bronchiectasis score ( $0-100,0$ worst to 100 best) } \\
\hline Physical functioning & $50.7 \pm 29.2$ & $51.3 \pm 30.2$ & $68.3 \pm 30.0$ & .12 \\
\hline Role functioning & $58.7 \pm 9.3$ & $51.7 \pm 12.6$ & $58.7 \pm 12.0$ & .12 \\
\hline Vitality & $55.6 \pm 14.8 \ddagger$ & $62.2 \pm 12.2$ & $67.6 \pm 12.4$ & $.045 \dagger$ \\
\hline Emotional functioning & $82.5 \pm 14.9$ & $81.3 \pm 21.1$ & $84.0 \pm 15.2$ & .87 \\
\hline Social functioning & $54.2 \pm 21.3$ & $56.3 \pm 23.7$ & $64.3 \pm 22.9$ & .37 \\
\hline Health perception & $45.0 \pm 17.7$ & $48.3 \pm 16.8$ & $43.0 \pm 14.4$ & .54 \\
\hline Respiratory symptoms & $64.5 \pm 23.1$ & $67.7 \pm 17.9$ & $73.0 \pm 18.6$ & .44 \\
\hline \multicolumn{5}{|l|}{ Leicester Cough Questionnaire score $(1-7,1$ worst to 7 best $)$} \\
\hline Physical & $4.59 \pm 1.92$ & $4.86 \pm 1.37$ & $5.19 \pm 1.27$ & .50 \\
\hline Psychological & $4.97 \pm 2.00$ & $5.14 \pm 1.51$ & $5.50 \pm 1.33$ & .58 \\
\hline Social & $5.25 \pm 1.65$ & $5.45 \pm 1.31$ & $5.63 \pm 1.16$ & .73 \\
\hline Total score & $14.8 \pm 5.4$ & $15.4 \pm 3.9$ & $16.3 \pm 3.5$ & .57 \\
\hline \multicolumn{5}{|l|}{$\begin{array}{l}\text { All values are expressed as mean } \pm \text { SD or } n . \\
* \text { Group } 2 \text { versus Group } 3(P<.05) . \\
\dagger \text { Significant between-group differences. } \\
\ddagger \text { Group } 1 \text { versus Group } 3(P<.05) . \\
\text { NA }=\text { not applicable } \\
\text { BMI }=\text { body mass index } \\
\text { MST }=\text { modified shuttle test } \\
\text { VAS }=\text { visual analogue scale }\end{array}$} \\
\hline
\end{tabular}

Table 3. Physical Activity Levels Across the Stages of Physical Activity Behavior Change

\begin{tabular}{|c|c|c|c|c|}
\hline Measures & $\begin{array}{l}\text { Pre-Contemplation and Contemplation } \\
\text { (Group } 1 ; n=10 \text { ) }\end{array}$ & $\begin{array}{c}\text { Preparation } \\
(\text { Group } 2 ; n=20)\end{array}$ & $\begin{array}{l}\text { Action and Maintenance } \\
\quad(\text { Group } 3 ; n=25)\end{array}$ & $P$ \\
\hline Light-lifestyle physical activity time, $\mathrm{min} / \mathrm{d}$ & $180 \pm 71$ & $189 \pm 44 *$ & $232 \pm 65$ & $.02 \dagger$ \\
\hline Total MVPA time, $\mathrm{min} / \mathrm{d}$ & $16.4 \pm 10.1 \neq$ & $18.4 \pm 15.5^{*}$ & $33.1 \pm 22.4$ & $.01 \dagger$ \\
\hline MVPA in $\geq 10$ - $\min$ bouts, $\mathrm{min} / \mathrm{d}$ & $1.45 \pm 3.06$ & $6.08 \pm 8.09$ & $8.26 \pm 10.96$ & .14 \\
\hline Total physical activity time, $\mathrm{min} / \mathrm{d}$ & $196 \pm 77 \ddagger$ & $207 \pm 52 *$ & $265 \pm 79$ & $.01 \dagger$ \\
\hline Daily step count, no. & $4,657 \pm 2,399 \ddagger$ & $5,170 \pm 2,494^{*}$ & $7,204 \pm 2,732$ & $.01 \dagger$ \\
\hline Activity energy expenditure, $\mathrm{kcal} / \mathrm{d}$ & $227 \pm 111$ & $279 \pm 156$ & $366 \pm 211$ & .08 \\
\hline Sedentary behavior time, $\mathrm{min} / \mathrm{d}$ & $644 \pm 50$ & $636 \pm 47$ & $627 \pm 102$ & .83 \\
\hline $\begin{array}{l}\text { All values are expressed as mean } \pm \text { SD. } \\
* \text { Group } 2 \text { versus Group } 3(P<.05) \text {. } \\
\dagger \text { Significant between-group differences. } \\
\ddagger \text { Group } 1 \text { versus Group } 3(P<.05) \text {. } \\
\text { MVPA }=\text { moderate to vigorous physical activity }\end{array}$ & & & & \\
\hline
\end{tabular}


Table 4. Marcus's Self-efficacy, Decisional Balance, and Processes of Change Scores Across the Stages of Physical Activity Behavior Change

\begin{tabular}{|c|c|c|c|c|}
\hline Constructs of the Transtheoretical Model* & $\begin{array}{l}\text { Pre-Contemplation } \\
\text { and Contemplation } \\
(\text { Group } 1 ; n=10)\end{array}$ & $\begin{array}{c}\text { Preparation } \\
(\text { Group } 2 ; n=20)\end{array}$ & $\begin{array}{c}\text { Action and } \\
\text { Maintenance } \\
\text { (Group } 3 ; n=25)\end{array}$ & $P$ \\
\hline \multicolumn{5}{|l|}{$\begin{array}{l}\text { Self-efficacy }(1-5,1 \text { not at all confident to } 5 \text { very } \\
\text { confident in being active) }\end{array}$} \\
\hline Mean self-efficacy score from 6 questions & $2.30 \pm 0.91$ & $2.32 \pm 0.89$ & $2.76 \pm 0.73$ & .14 \\
\hline Self-efficacy when having respiratory symptoms & $1.30 \pm 0.67$ & $1.50 \pm 0.95$ & $1.92 \pm 1.04$ & .15 \\
\hline \multicolumn{5}{|l|}{ Decisional balance } \\
\hline $\begin{array}{l}\text { Pros (1-5, higher scores perceive more benefits in } \\
\text { being active) }\end{array}$ & $3.58 \pm 0.47$ & $3.57 \pm 0.98$ & $3.47 \pm 1.04$ & .92 \\
\hline $\begin{array}{l}\text { Cons (1-5, higher scores perceive more barriers } \\
\text { in being active) }\end{array}$ & $2.75 \pm 0.47$ & $2.90 \pm 0.80 \dagger$ & $2.34 \pm 0.72$ & $.034 \ddagger$ \\
\hline $\begin{array}{l}\text { Decisional balance score (difference between pros } \\
\text { minus cons; scores }>0 \text { indicate perceptions of } \\
\text { more benefits than barriers to being physically } \\
\text { active) }\end{array}$ & $0.83 \pm 0.68$ & $0.67 \pm 1.15$ & $1.13 \pm 1.00$ & .31 \\
\hline \multicolumn{5}{|l|}{$\begin{array}{l}\text { Processes of change }(1-5 \text {, higher scores indicate } \\
\text { greater usage of strategies to become more } \\
\text { active) }\end{array}$} \\
\hline $\begin{array}{l}\text { Cognitive processes of change (mean score of } 5 \\
\text { domains) }\end{array}$ & $2.81 \pm 0.93$ & $2.70 \pm 0.81$ & $2.38 \pm 0.67$ & .22 \\
\hline Increasing knowledge (consciousness raising) & $2.68 \pm 0.84$ & $2.46 \pm 0.68$ & $2.43 \pm 0.91$ & .72 \\
\hline Being aware of risks (dramatic relief) & $2.48 \pm 1.08$ & $2.51 \pm 1.19$ & $2.16 \pm 0.82$ & .47 \\
\hline $\begin{array}{l}\text { Caring about consequences (environmental } \\
\text { re-evaluation) }\end{array}$ & $2.85 \pm 1.11$ & $2.80 \pm 1.10$ & $2.16 \pm 0.86$ & .061 \\
\hline Comprehending benefits (self-re-evaluation) & $3.40 \pm 1.02$ & $3.35 \pm 1.08$ & $2.92 \pm 0.92$ & .26 \\
\hline Increasing healthy opportunities (social liberation) & $2.65 \pm 1.16$ & $2.35 \pm 0.94$ & $2.21 \pm 0.87$ & .47 \\
\hline $\begin{array}{l}\text { Behavioral processes of change (mean score of } 5 \\
\text { domains) }\end{array}$ & $2.30 \pm 0.87$ & $2.68 \pm 0.68$ & $2.58 \pm 0.65$ & .37 \\
\hline Substituting alternatives (counterconditioning) & $2.30 \pm 1.15 \S$ & $2.91 \pm 0.80$ & $3.33 \pm 0.91$ & $.01 \ddagger$ \\
\hline Enlisting social support (helping relationships) & $2.38 \pm 0.71$ & $2.78 \pm 0.99 \dagger$ & $2.10 \pm 0.86$ & $.049 \ddagger$ \\
\hline Rewarding oneself (reinforcement management) & $2.13 \pm 1.10$ & $2.63 \pm 0.99$ & $2.42 \pm 0.83$ & .39 \\
\hline Committing oneself (self-liberation) & $2.73 \pm 1.00$ & $3.14 \pm 0.91$ & $3.16 \pm 0.98$ & .45 \\
\hline Reminding oneself (stimulus control) & $1.95 \pm 0.96$ & $1.96 \pm 0.73$ & $1.88 \pm 0.64$ & .93 \\
\hline \multicolumn{5}{|l|}{$\begin{array}{l}\text { All values are expressed as mean } \pm \text { SD. } \\
* \text { See Table } 1 \text { for definitions of each construct of the transtheoretical model. } \\
\dagger \text { Group } 2 \text { versus Group } 3(P<.05) \text {. } \\
\text { † Significant between-group differences. } \\
\S \text { Group } 1 \text { versus Group } 3(P<.05) \text {. }\end{array}$} \\
\hline
\end{tabular}

substituting alternatives compared with Group $3(-1.03$, $95 \% \mathrm{CI}:-1.86$ to $-0.20, P=.01)$, whereas Group 2 enlisted social support significantly more compared with Group 3 (0.68, 95\% CI: $0.31-1.32, P=.038)$.

Exploratory analyses showed that Group 1 used significantly more cognitive processes of change compared with behavioral processes of change $(0.52,95 \% \mathrm{CI}$ : $0.06-0.97$, $P=.031)$, Group 2 used similar amounts of cognitive and behavioral processes of change $(P=.92)$, and Group 3 used more behavioral processes of change compared with cognitive processes of change $(P=.055)$.

\section{Discussion}

This research aimed to examine the application of each construct of the transtheoretical model in subjects with bronchiectasis. The stage distribution of subjects in this study is similar to those in studies exploring the application of the transtheoretical model with other healthy ${ }^{24}$ and clinical populations, ${ }^{20}$ including those with respiratory disease. ${ }^{25}$ In the majority of studies, most subjects report that they were in either a preparation or maintenance stage. In general, the results give some indication of a pattern of healthier clinical phenotype with higher stages of change. In particular, subjects in lower stages of change achieved significantly lower modified shuttle test distances and had lower Quality of Life Questionnaire-Bronchiectasis vitality scores. Distance walked during the incremental shuttle walk test has recently been shown to be significantly and positively correlated with daily step counts in subjects with bronchiectasis. ${ }^{46} \mathrm{~A}$ number of the other clinical phe- 
notype outcomes showed a similar pattern, although this failed to reach significance. Lung function and disease severity did not show a pattern between groups. This is unsurprising because the results from the Physical Activity in Bronchiectasis ${ }^{10}$ study showed that both lung function and disease severity were not correlates of physical activity in bronchiectasis.

\section{Patterns in Physical Activity and Sedentary Behavior Across Stages of Change}

The results show a consistent pattern of lower levels of physical activity across lower stages of change. The transtheoretical model predicts that individuals who report a lower stage of change will have a lower level of physical activity. The ActiGraph physical activity variables measured in this study support this hypothesis. This is also in agreement with other research studies conducted in healthy ${ }^{47}$ and clinical populations, such as diabetes. ${ }^{20}$ The Stages of Change Questionnaire is easy to complete and is the most commonly used element of the transtheoretical model. This simple questionnaire could potentially be used within routine practice to identify individuals who have low levels of physical activity and therefore individuals who should be targeted for physical activity interventions using specific strategies.

This study showed no significant patterns in sedentary behavior across the stages of change. This is not surprising because the Stages of Change Questionnaire was developed in reference to physical activity. As has been stated previously, sedentary behavior has been identified as an independent risk factor for various chronic diseases. ${ }^{48}$ Therefore, it may be important for future research to adapt the Stages of Change Questionnaire if sedentary behavior is the key behavior of interest.

\section{Patterns in Mediators of Change Across Stages of Change}

In general, only small differences were found in the mediators of change across stages of change. Subjects in the preparation stage perceived significantly more barriers to being physically active compared with subjects in action and maintenance stages. For processes of change, subjects in pre-contemplation and contemplation stages used significantly fewer substituting alternatives compared with subjects in the action and maintenance stages, whereas subjects in the preparation stage enlisted social support significantly more compared with subjects in action and maintenance stages. This means that subjects in higher stages of change more often substituted inactive options with active options but used less social support from friends and family compared with subjects in lower stages. In general, subjects in pre-contemplation and contemplation stages used significantly more cognitive processes of change compared with behavioral processes of change, subjects in the preparation stage used similar amounts of cognitive and behavioral processes of change, and subjects in action and maintenance stages used more behavioral processes of change compared with cognitive processes of change. This is consistent with the predictions of the transtheoretical model and with previous research ${ }^{25,47}$ and suggests that interventions for individuals in earlier stages of change should focus more on cognitive processes of change, whereas behavioral processes should be used more in later stages of change. The most commonly used cognitive process across all stages of change was comprehending benefits, and the most commonly used behavioral processes were substituting alternatives (action and maintenance stages) and committing oneself (all stages). This is consistent with previous research exploring processes of change used by subjects with COPD. ${ }^{25}$ This further suggests that interventions should focus on these processes to support physical activity behavior change in respiratory disease populations.

\section{Application of the Transtheoretical Model to Physical Activity Interventions in Bronchiectasis}

Overall, the findings appear to support the application of the transtheoretical model to physical activity in bronchiectasis. This means that the transtheoretical model could potentially be utilized as a theoretical framework when designing individualized interventions to improve physical activity levels in patients with bronchiectasis. For example, in clinical practice or research, the goal of a physical activity intervention may be to facilitate movement from the contemplation stage of change to the preparation stage of change. In order to do this, strategies could be introduced to ensure optimal usage of the cognitive processes of change before attempting to increase behavioral processes of change. These may include: assessing how people feel about being physically inactive, introducing a physically active role model, increasing awareness of how being physically active could benefit significant others, and providing education and/or feedback on the negative health consequences of being physically inactive and also how to counteract these consequences. These strategies would be expected to impact positively on self-efficacy for being physically active in different situations (such as during bad weather and when having respiratory symptoms) and also on decisional balance (reduction in perceived barriers to being physically active and an increase in perceived benefits of being physically active).

Another example of a physical activity intervention goal could be to facilitate movement from the preparation stage of change to the action stage of change. In order to do this, strategies could be introduced to increase and optimize 
usage of behavioral processes of change. These may include: increasing recognition and usage of active options over inactive options (such as parking farther away from shops to walk farther), establishing a walking group for patients with bronchiectasis to help encourage social support in being physically active, developing suitable reward schemes to encourage positive physical activity choices, and developing action plans with realistic goals to help create a commitment to change physical activity behavior. As in the previous example, further positive changes in self-efficacy and decisional balance would be expected as a result of these strategies. Taking these graduated approaches to changing physical activity behavior will hopefully lead to an increase in physical activity parameters, such as light-lifestyle physical activity, total moderate to vigorous physical activity, and step counts.

\section{Study Strengths and Limitations}

Currently, the literature on physical activity in bronchiectasis is limited. This study adds significantly to this area of literature by providing a thorough exploration of the application of the transtheoretical model within this respiratory disease group. This information is important for improving accuracy in understanding and predicting physical activity behavior and for the development of future physical activity interventions tailored to this respiratory disease group. The study has particular strength in its inclusion of each component of the transtheoretical model and in the use of an objective method in measuring physical activity. One of the most important limitations of this study was the small number of subjects in each group. However, each stage of change was represented, and analysis was conducted exploring patterns across individual stages and also in 3 collapsed groups.

\section{Conclusions}

This is the first study to examine the application of each construct of the transtheoretical model in individuals with bronchiectasis. In general, the findings from this study support the theoretical predictions of the transtheoretical model and the application of this model for physical activity intervention development in bronchiectasis. Constructs of the transtheoretical model that appear to be important at different stages of change include decisional balance cons, substituting alternatives, and enlisting social support. Future work should explore the effectiveness of transtheoretical model-based physical activity interventions in this respiratory disease group and explore whether all dimensions or even new components should be investigated. Future work should also explore the longitudinal change of transtheoretical model variables as a result of intervention.

\section{REFERENCES}

1. Lavery K, O’Neill B, Elborn JS, Reilly J, Bradley JM. Self-management in bronchiectasis: the patients' perspective. Eur Respir J 2007; 29(3):541-547.

2. O'Donnell AE. Bronchiectasis. Chest 2008;134(4):815-823.

3. Pasteur MC, Bilton T, Hill AT, British Thoracic Society Bronchiectasis non-CF Guideline Group. British Thoracic Society guideline for non-CF Bronchiectasis. Thorax 2010;65(Suppl 1):i1-i58.

4. Weycker D, Edelsberg J, Oster G, Tino G. Prevalence and economic burden of bronchiectasis. Clin Pulm Med 2005;12(4):205-209.

5. Gibson GJ, Loddenkemper R, Lundback B, Sibille Y. The European Lung White Book. Sheffield: European Respiratory Society; 2013.

6. McCullough AR, Tunney MM, Quittner AL, Elborn JS, Bradley JM, Hughes CM. Treatment adherence and health outcomes in patients with bronchiectasis. BMC Pulm Med 2014;14:107.

7. Department of Health, Social Services and Public Safety. Service framework for respiratory health and well being. November 2009. http://www.dhsspsni.gov.uk. Accessed Jan 12, 2015.

8. Bolton CE, Bevan-Smith EF, Blakey JD, Crowe P, Elkin SL, Garrod $\mathrm{R}$, et al. British Thoracic Society guideline on pulmonary rehabilitation in adults: accredited by NICE. Thorax 2013;68(Suppl 2):ii1ii30.

9. Gimeno-Santos E, Frei A, Steurer-Stey C, de Batlle J, Rabinovich RA, Raste Y, et al. Determinants and outcomes of physical activity in patients with COPD: a systematic review. Thorax 2014;69(8):731739.

10. Bradley JM, Wilson JJ, Hayes K, Kent L, McDonough S, Tully MA, et al. Sedentary behaviour and physical activity in bronchiectasis: a cross-sectional study. BMC Pulm Med 2015;15:61.

11. Craig P, Dieppe P, Macintyre S, Michie S, Nazareth I, Petticrew M, Medical Research Council Guidance. Developing and evaluating complex interventions: the new Medical Research Council guidance. BMJ 2008;337:a1655.

12. Prestwich A, Sniehotta FF, Whittington C, Dombrowski SU, Rogers L, Michie S. Does theory influence the effectiveness of health behavior interventions? Meta-analysis. Health Psychol 2014;33(5):465474.

13. Michie S, Abraham C. Interventions to change health behaviours: evidence-based or evidence-inspired? Psychol Health 2004;19(1): 29-49.

14. Greaves CJ, Sheppard KE, Abraham C, Hardeman W, Roden M, Evans PH, Schwarz P. Systematic review of reviews of intervention components associated with increased effectiveness in dietary and physical activity interventions. BMC Public Health 2011;11:119.

15. Wilson JJ, O'Neill B, Collins EG, Bradley J. Interventions to increase physical activity in patients with COPD: a comprehensive review. COPD 2015;12(3):332-343.

16. Bandura A. Social foundations of thought and action: a social cognitive theory. Englewood Cliffs, NJ: Prentice Hall; 1986.

17. Biddle SJ, Mutrie N. Psychology of physical activity: determinants, well-being and interventions. 2nd edition. Abingdon, UK: Routledge 2008:118-136.

18. Michie S, Ashford S, Sniehotta FF, Dombrowski SU, Bishop A, French DP. A refined taxonomy of behaviour change techniques to help people change their physical activity and healthy eating behaviours: the CALORE taxonomy. Psychol Health 2011;26(11):14791498.

19. Hutchison AJ, Breckon JD, Johnston LH. Physical activity behavior change interventions based on the transtheoretical model: a systematic review. Health Educ Behav 2009;36(5):829-845.

20. Kirk A, MacMillan F, Webster N. Application of the transtheoretical model to physical activity in older adults with type 2 diabetes and/or cardiovascular disease. Psychol Sport Exerc 2010;11(4):320-324. 
21. Ashmore J, Russo R, Peoples J, Sloan J, Jackson BE, Bae S, et al. Chronic obstructive pulmonary disease self-management activation research trial (COPD-SMART): Design and methods. Contemp Clin Trials 2013;35(2):77-86.

22. Marcus BH, Simkin LR. The transtheoretical model: applications to exercise behavior. Med Sci Sports Exerc 1994;26(11):1400-1404.

23. Marcus BH, Forsyth LH. Motivating people to be physically active, 2nd edition. Champaign, IL: Human Kinetics; 2009:3-20.

24. Nigg CR, Geller KS, Motl RW, Horwath CC, Wertin KK, Dishman RK. A research agenda to examine the efficacy and relevance of the transtheoretical model for physical activity behavior. Psychol Sport Exerc 2011;12(1):7-12.

25. Yang PS, Chen $\mathrm{CH}$. Exercise stage and processes of change in patients with chronic obstructive pulmonary disease. J Nurs Res 2005; 13(2):97-105.

26. European Cystic Fibrosis Society Clinical Trial Network (ECFSCTN) Standardisation Committee. Modified Shuttle Test for Clinical Trials within the ECFS-CTN (Version 1): Karup, Denmark: European Cystic Fibrosis Society; 2012.

27. Miller MR, Hankinson J, Brusasco V, Burgos F, Casaburi R, Coates A, et al. Standardisation of spirometry. Eur Respir J 2005;26(2):319338.

28. Chalmers JD, Goeminne P, Aliberti S, McDonnell MJ, Lonni S, Davidson J, et al. The bronchiectasis severity index: an international derivation and validation study. Am J Respir Crit Care Med 2014; 189(5):576-585.

29. Bradley J, Howard J, Wallace E, Elborn S. Validity of a modified shuttle test in adult cystic fibrosis. Thorax 1999;54(5):437-439.

30. Bradley J, Howard J, Wallace E, Elborn S. Reliability, repeatability and sensitivity of the modified shuttle test in adult CF. Chest 2000; 117(6):1666-1671.

31. Herdman M, Gudex C, Lloyd A, Janssen M, Kind P, Parkin D, et al. Development and preliminary testing of the new five-level version of EQ-5D (EQ-5D-5L). Qual Life Res 2011;20(10):1727-1736.

32. Rabin R, Oemar M, Oppe M, Janssen B, Herdman M. EQ-5D-5L user guide: basic information on how to use the EQ-5D-5L instrument. Rotterdam, The Netherlands: EuroQOL Group; 2011.

33. EuroQol Group. EQ-5D-5L value sets. November 2014. http:// www.euroqol.org/about-eq-5d/valuation-of-eq-5d/eq-5d-51-valuesets.html. Accessed December 13, 2014.

34. Quittner AL, Marciel KK, Salathe MA, O'Donnell AE, Gotfried $\mathrm{MH}$, Ilowite JS, et al. A preliminary Quality of Life QuestionnaireBronchiectasis: a patient-reported outcome measure for bronchiectasis. Chest 2014;146(2):437-448.
35. Birring SS, Prudon B, Carr AJ, Singh SJ, Morgan MDL, Pavord ID. Development of a symptom specific health status measure for patients with chronic cough: the Leicester Cough Questionnaire (LCQ). Thorax 2003;58(4):339-343.

36. Choi L, Liu Z, Matthews CE, Buchowski MS. Validation of accelerometer wear and nonwear time classification algorithm. Med Sci Sports Exerc 2011;43(2):357-364.

37. Gretebeck RJ, Montoye HJ. Variability of some objective measures of physical activity. Med Sci Sports Exerc 1992;24(10):1167-1172.

38. Trost SG, McIver KL, Pate RR. Conducting accelerometer-based activity assessments in field-based research. Med Sci Sports Exerc 2005;37(11 Suppl):S531-S543.

39. Freedson PS, Melanson E, Sirard J. Calibration of the Computer Science and Applications, Inc. accelerometer. Med Sci Sports Exerc 1998;30(5):777-781.

40. Hart TL, Swartz AM, Cashin SE, Strath SJ. How many days of monitoring predict physical activity and sedentary behaviour in older adults? Int J Behav Nutr Phys Act 2011;8:62-63.

41. Loughlan C, Mutrie N. Recruitment of sedentary NHS staff for a workplace exercise programme using an adapted "stages of change" exercise questionnaire. J Sports Sci 1995;13:63-64.

42. Marcus BH, Selby VC, Niaura RS, Rossi JS. Self-efficacy and the stages of exercise behavior change. Res Q Exerc Sport 1992;63(1): 60-66.

43. Marcus BH, Rakowski W, Rossi JS. Assessing motivational readiness and decision making for exercise. Health Psychol 1992;11(4): 257-261.

44. Marcus BH, Rossi JS, Selby VC, Niaura RS, Abrams DB. The stages and processes of exercise adoption and maintenance in a worksite sample. Health Psychol 1992;11(6):386-395.

45. Fahrenwald NL, Walker SN. Application of the transtheoretical model of behavior change to the physical activity behavior of WIC mothers. Public Health Nurs 2003;20(4):307-317.

46. de Camargo AA, Amaral TS, Rached SZ, Athanazio RA, Lanza FC, Sampaio LM, et al. Incremental shuttle walking test: a reproducible and valid test to evaluate exercise tolerance in adults with noncystic fibrosis bronchiectasis. Arch Phys Med Rehabil 2014;95(5):892-899.

47. Marshall SJ, Biddle SJ. The transtheoretical model of behavior change: a meta-analysis of applications to physical activity and exercise. Ann Behav Med 2001;23(4):229-246.

48. Hamilton MT, Healy GN, Dunstan DW, Zderic TW, Owen N. Too little exercise and too much sitting: inactivity physiology and the need for new recommendations on sedentary behavior. Curr Cardiovasc Risk Rep 2008;2(4):292-298. 